Univ. of Pittsburgh Legal Studies Research Paper No. 2017-24

NYU School of Law, Law E Economics Research Paper No. 17-40

October 2017

\title{
GOVERNING MEDICAL KNOWLEDGE COMMONS - Introduction \& Chapter 1
}

From: GOVERNING MEDICAL KNOWLEDGE COMMONS, Katherine J. Strandburg, Brett M. Frischmann, and Michael J. Madison, eds.

(Cambridge University Press, 2017)

Katherine J. Strandburg

New York University - School of Law

E-mail: katherine.strandburg@nyu.edu

Brett M. Frischmann

Villanova - School of Law

E-mail: brett.frischmann@law.villanova.edu

Michael J. Madison

University of Pittsburgh - School of Law

E-mail: madison@ @itt.edu 


\title{
Knowledge Commons and the Road to Medical Commons
}

\author{
Katherine I. Strandburg, Brett M. Frischmann, \\ and Michael J. Madison
}

This book picks up where Governing Knowledge Commons, our 2014 collection of perspectives and case studies of knowledge commons governance, left off. Governing Knowledge Commons (GKC) laid down a research program that contributes to evidence-based policymaking about innovation and creative knowledge production, as well as the creation, preservation, and uses of existing and new knowledge. The cases presented in GKC are, in a word, diverse. They range from arts to sciences, from the professions to popular culture, from historical to contemporary. Governing Medical Knowledge Commons sustains that research program but with a specific, thematic focus. This book collects and presents a series of case studies of knowledge commons centered on recent and emerging experience in the life sciences, medical research, and medical practice.

\section{FOUNDATIONS}

We reiterate anew some key, foundational themes and principles that underlie the research program and the expanding set of cases that implement and illustrate it. First is the proposition that both "commons" as a general concept and "knowledge commons" as the particular concept that frames this work describe modes of governance of resources - sustained, systematized sharing - rather than a place (such as a literal or metaphorical open ground) or a political or philosophical commitment (such as unregulated openness, use, or access). Our intuition, shared by many, is that commons governance has much to offer society in terms of innovation, growth, and other

Katherine J. Strandburg is the Alfred B. Engelberg Professor of Law and a Faculty Director of the Engelberg Center for Innovation Law and Policy at the New York University School of Law, New York. Brett M. Frischmann is The Charles Widger Endowed University Professor in Law, Business and Economics at Villanova University Charles Widger School of Law, Villanova, Pennsylvania. Michael J. Madison is Professor of Law and Faculty Director of the Innovation Practice Institute at the University of Pittsburgh School of Law, Pittsburgh, Pennsylvania. Professor Strandburg acknowledges the generous support of the Filomen D'Agostine and Max E. Greenberg Research Fund. 
forms of social welfare but also that knowledge commons is no panacea. The tough work of systematized research is needed to understand the strengths and weaknesses of knowledge commons at different times and in different contexts.

Second is the proposition that knowledge commons research takes an explicitly institutional perspective on the challenges of understanding processes of innovation; creativity; and knowledge and information production, preservation, and consumption. A great deal of intellectual property law and policy analysis and decision making adopts the perspective of the individual actor or firm, and the individual invention, creative work, or specific item of knowledge or information. We argue that this important work can only be effectively understood and applied if it is situated in the larger context of institutions, which include both formal entities and informal but regular patterns of economic and other social interaction. Knowledge production is ecological and environmental.

As in GKC, therefore, we embrace the analogy between the cultural environment and the natural environment (Boyle 2008; Frischmann 2007) to explore the proposition that just as natural resources often are governed by commons rather than being managed as either public or private property, the production and sharing of knowledge often are sustained by commons governance. We continue to borrow from researchers of the natural resource environment who have developed successful methods for studying commons arrangements systematically and in detail. Our knowledge commons research framework adopts the style of and begins with the Institutional Analysis and Development (IAD) framework developed and used by Elinor Ostrom and others. Our GKC framework adapts the IAD framework to speak to the unique attributes of knowledge and information.

The third foundational proposition underlying our work is that knowledge commons governance involves both law and other modes of governance. This is more than "law in action" or "law in society"; it is attempting to understand the actual role that law plays in constructing and sustaining effective resource governance - or, at times, in failing to sustain it. In some contexts, intellectual property law and other formal law play critical roles in ensuring the continued supply of new knowledge and other innovation. In other contexts, either intellectual property law or other law or both are all but invisible and absent. And in many contexts, knowledge production depends on distinct blends of law and other norms, both formal and informal.

Our fourth and final starting point is that the knowledge commons research program is intentionally designed as a learning exercise, so that the results of each iteration of knowledge commons research informs and helps refine the structure of the next round. The conclusion of GKC teaches that the research framework as initially specified did not quite capture aspects of knowledge commons that appeared repeatedly in GKC's collection of case studies (Frischmann, Madison, and Strandburg 2014, at 469-84). The framework as applied and described in this book has been updated as a result, and we anticipate further revisions and refinements in the future: 


\section{BUILDING THE FRAMEWORK}

This project grew initially out of our shared interest in the functioning of systems of intellectual property rights - patent, copyright, and related bodies of law - and how those systems relate to now-abundant examples of institutions that support collaborative creativity and innovation. Wikipedia is a canonical, almost trite example, but we recognize that collaborative production of new knowledge is neither truly novel (though modern computer networks appear to have increased its power and visibility dramatically) nor rare. Whether one looks at online encyclopedias, or patent pools as they began to emerge during the nineteenth century, or the system of correspondence known as the Republic of Letters that energized scientific discovery during the seventeenth and eighteenth centuries (Mokyr 2002), it appears to be clear that systems of collaborative production have been critical parts of knowledge production for centuries, in both arts and sciences. The research questions that these raise consist not merely of "why would people contribute?" but more importantly "in cultural, economic, and legal terms, how do such institutions function, how have they evolved, and how are they likely to evolve in the future?"

The existence, indeed abundance, of knowledge commons institutions challenges the traditional perspective of many intellectual property law scholars, who divide the world of innovation and creativity production into two default categories: innovation systems organized around markets, supported by intellectual property rights directed to exclusivity and ownership, and innovation systems organized around governments, which intervene in markets (or avoid markets) in various ways to sponsor and subsidize innovation. A third approach, commons-based sharing of knowledge and information resources to produce innovation and creativity, had typically been omitted - though, through GKC and other research, it is increasingly acknowledged. We aim to continue to move that third approach beyond the conceptual, and beyond its occasional positioning as a rhetorical device imposed to stifle the expansion of intellectual property protection (Hyde 2010). Empirical study of norm- and custom-based innovation communities, sometimes collected under the label "IP [Intellectual Production] without IP [Intellectual Property]," often is developed in opposition to (and therefore in reliance on) market-based presumptions of the need for exclusivity, substituting norm-based exclusivity for legally defined intellectual property (Perzanowski and Darling 2017). Our knowledge commons research program and the IP without IP strand of IP scholarship share an interest in detailed empirical investigation in innovation and creativity institutions and practices, an interest in understanding the roles and limits of formal IP systems, and a desire to break free of the exclusive rights in markets vs. government intervention duality that has long characterized policy discussions regarding innovation and knowledge production. But our research program is distinct in adopting a particular framework for systematizing that research and in its expansive view of governance dilemmas and institutions. 
One of our continuing goals, in other words, is to stake out knowledge commons governance as an independent, affirmative means for producing innovation and creativity and an important domain for research. In our view, commons are not wholly independent of or opposed to markets based on exclusive rights (whether formal or informal), neither are they subordinate to them.

Our perspective is inspired by the comparative institutional analysis approach of the Nobel Prize-winning research of the late Elinor Ostrom, who was best known for her lifetime of research into the functioning of commons governance, especially in the natural resources context. Ostrom was far from the first scholar to examine resource systems and governance using an institutionalist lens. But her work and that of her collaborators and successors highlighted commons as an object of study in a way that no scholar had done before. Ostrom also approached the topic with an extraordinary humility and disciplinary generosity, recognizing that understanding this complex area could only be achieved through the contributions of researchers from many fields, aligned via a shared research framework that could accommodate a variety of disciplines and methods. Her impact was magnified by her emphasis on a shared research framework accessible to and usable by numerous disciplines and throughout the world. In all of our work on knowledge commons, we have tried to adopt both the spirit and style of Ostrom's work.

Toward the end of Ostrom's career, she and her colleagues recognized the emerging importance of knowledge commons as an area for sustained research and began to apply the IAD framework to them (Ostrom and Hess 2006; Hess 2012). In 2010, we developed a research framework inspired by the IAD framework but specifically tailored to the properties that distinguish knowledge and information from natural resources (Madison, Frischmann, and Strandburg 2010). That framework, with some elaborations and clarifications, follows this introduction as Chapter 1 of this book.

\section{ORGANIZATION OF THE BOOK}

The knowledge commons research framework is presented in Chapter 1. We provide both a thorough explanation of the framework and a short, almost "pocket-sized" version, anticipating that additional researchers may want to use the framework and improve on it in their own studies of knowledge commons. Both the framework and overviews of both this book and GKC are available at a dedicated website, http://knowledge-commons.net, for the benefit of researchers developing new case studies and data analyses.

After the framework come 15 case studies of knowledge commons in the medical context, which we characterize as cases of "medical commons," from a group of interdisciplinary researchers. These cases continue the detailed exploration of how knowledge commons function, the place they occupy in the cultural environment, the specific benefits they offer, the costs and risks they create, and their relationships 
to other institutional structures. The case study authors come from a variety of research traditions, offering a variety of perspectives on life sciences, health, and medicine but unified via their shared application of the knowledge commons framework. GKC offered an initial demonstration of the value of studying knowledge commons carefully, in a comparative fashion, to develop evidence of the details of their purposes and operations. This book drills down to study knowledge commons in a particular subject area. In time, the data collected in these and other knowledge commons case studies should provide insights into how to design and/or harness knowledge commons for broad public benefit.

Scientific research and medical research are domains in which knowledge commons governance has long been a primary institutional approach. Researchers often share resources and infrastructure that include background scientific and medical information, data, techniques, materials, and devices. The first cluster of case studies, in Chapters 2 through 8, develops and applies the knowledge commons research framework to commons arrangements for pooling and governing biological data, biomedical data, and scientific research data in the life sciences and medicine. Traditional intellectual property rights are unlikely to play important roles in governing data sharing by virtue of the weak IP rights that ordinarily apply to data, data sets, and collections of data. Yet researchers have strong interests in data production, coordination, and sharing, which prompt the formation of robust modes of commons-based institutional governance. In Chapter 2, Jorge Contreras addresses the development of several different collections of human genomic data. Peter Lee's Chapter 3 explores the management of the genomic data commons via the tools and techniques deployed in its construction and analysis. In Chapter 4, Barbara Evans further discusses the use of genomic data for genetic testing. Andrea Boggio follows that chapter with a case study addressing biobanks and their associated data collections, particularly population-level biobanks. In Chapter 6, Ryan Abbott describes commons governance attributes of the U.S. Food and Drug Administration's Sentinel Initiative, an effort to collect and analyze public health data associated with the safety of medical products. Michael Mattioli follows that chapter with a case study of a collaborative of institutions focused on the collection and analysis of oncology treatment data. This section of the book concludes in Chapter 8 with a case study by Maja Larson and Margaret Chon of the open neuroscience movement and its efforts to collect and distribute research data.

Research-related and therapeutic tools, materials, and techniques may be governed as commons either in spite of or by building alongside traditional or conventional intellectual property regimes. Chapters 9 and 10 describe knowledge commons governance of innovations in the production of health and medicinerelated devices and clinical therapies. In Chapter 9, Andrew Torrance reviews knowledge commons institutions that are constructing the emerging field of synthetic biology, or the production of engineered human tissues. In Chapter 10, 
Tania Bubela and her colleagues describe commons governance of the production of research tools, engineered mice, that are critical to the translation of laboratory and clinical science to medically useful therapies.

Clinical research and clinical care are the subjects of the final group of case studies, in which traditional intellectual property systems may be absent, on historical or ethical grounds, or insufficient in other respects. Some of these case studies focus on commons governance by providers of medical care and some focus on governance by or including patients themselves. In Chapter 11, Laura Pedraza-Fariña provides a case study of the collaborative production of techniques for fertility care for oncology patients. In Chapter 12, Glenn Saxe and Mary Acri describe a case of knowledge commons governance of the delivery of mental health services, drawing not only on the knowledge commons research framework but also on existing research on user innovation. Pedro Oliveira and his colleagues follow in Chapter 13 with a description of a project for pooling patient and caregiver innovations in medical care. Again, user innovation perspectives are usefully combined with the knowledge commons framework. In Chapter 14, Stephen Flowers describes a group of patients creating and sharing innovation at the "outlaw" edge of standard medical research. Chapters 15 and 16 present the findings of case studies of two consortia operating under the umbrella of the Rare Diseases Clinical Research Network at the National Institutes of Health in the United States. In Chapter 15, Brett Frischmann and Katherine Strandburg describe the knowledge commons governance of the North American Mitochondrial Disease Consortium. In Chapter 16, Katherine Strandburg and Stefan Bechtold describe the knowledge commons governance of the Consortium for Eosinophilic Gastroinstestinal Disease Research.

As in GKC, a concluding chapter in this book highlights commonalities and differences among the knowledge commons studied here, draws relevant lessons with respect to knowledge commons research and knowledge commons in general, and looks forward to future studies. Knowledge commons do important work in the medical arena. The case studies in this book move us closer to understanding how and why.

\section{ACKNOWLEDGMENTS}

Our knowledge commons research efforts are now roughly a decade old. We are proud to note that on account of this long gestation, those efforts are now yielding more and more useful research products. The collaboration that underlies this book began in conversations among the editors about cultural commons and knowledge commons in 2006 and 2007. It took root with the publication of Madison, Frischmann, and Strandburg (2010) and with responses to that article from a group of generous scholars (Eggertson 2010; Gordon 2010; Macey 2010; Merges 2010; Ostrom 2010; Solum 2010). The collaboration continued in September 2011 as a number of researchers from around the world gathered at the Engelberg Center 
for Innovation Law and Policy at New York University School of Law for a workshop titled Convening Cultural Commons; many of the chapters in GKC were shared in early form in that setting. The case studies in this volume were shared in early form at a second workshop at the Engelberg Center in May 2014 that joined communities of researchers with backgrounds in intellectual property law and policy, on the one hand, and researchers with expertise in the domain of user innovation, a field pioneered by Eric von Hippel at MIT. As noted earlier, several of the chapters in this book suggest fruitful complements between knowledge commons research and user innovation research.

Each of us, as editors of this volume and participants in an emerging global enterprise for the study of knowledge commons, is grateful to the Engelberg Center for its continuing hospitality and support. We are also grateful for the openness with which the work has been received so far, for the generous critiques and conversations that our colleagues (both old and new) have shared, and for what we hope is a long, continuing discussion of this important topic.

\section{REFERENCES}

Boyle, James, The Public Domain: Enclosing the Commons of the Mind (Yale University Press 2008).

Eggertsson, Thráinn, Response: Mapping Social Technologies in the Cultural Commons, 95 Cornell L. Rev. 711 (2010).

Frischmann, Brett M., Cultural Environmentalism and The Wealth of Networks, 74 U. Chi. L. Rev. 1083 (2007).

Frischmann, Brett M., Michael J. Madison, and Katherine J. Strandburg (eds.), Governing Knowledge Commons (Oxford University Press 2014).

Gordon, Wendy J., Response: Discipline and Nourish: On Constructing Commons, 95 Cornell L. Rev. 733 (2010).

Hess, Charlotte, Constructing a New Research Agenda for Cultural Commons, in Cultural Commons: A New Perspective on the Production and Evolution of Cultures 19 (Enrico Bertacchini et al. eds., Edward Elgar Publishing 2012).

Hyde, Lewis, Common as Air: Revolution, Art, and Ownership (Farrar, Straus and Giroux 2010).

Macey, Gregg P., Response: Cooperative Institutions in Cultural Commons, 95 Cornell L. Rev. 757 (2010).

Madison, Michael J., Brett M. Frischmann, and Katherine J. Strandburg, Constructing Commons in the Cultural Environment, 95 Comell L. Rev. 657 (2010).

Merges, Robert P., Response: Individual Creators in the Cultural Commons, 95 Cornell L. Rev. 793 (2010).

Mokyr, Joel, The Gifts of Athena: Historical Origins of the Knowledge Economy (Princeton University Press 2002).

Ostrom, Elinor, Response: The Institutional Analysis and Development Framework and the Commons, 95 Cornell L. Rev. 807 (2010). 
Ostrom, Elinor, and Charlotte Hess, A Framework for Analyzing the Knowledge Commons, in Understanding Knowledge as a Commons: From Theory to Practice (Charlotte Hess and Elinor Ostrom eds., MIT Press 2006).

Perzanowski, Aaron, and Kate Darling (eds.), Creativity without Law: Challenging the Assumptions of Intellectual Property (New York University Press 2017).

Solum, Lawrence B., Response: Questioning Cultural Commons, 95 Cornell L. Rev. 817 (2010). 


\title{
The Knowledge Commons Framework
}

\author{
Katherine J. Strandburg, Brett M. Frischmann, \\ and Michael J. Madison
}

\subsection{INTRODUCTION}

This chapter sets out the knowledge commons framework that forms the foundation for the case study chapters that follow. ${ }^{1}$ The framework is inspired by and builds in part on the Institutional Analysis and Development (IAD) approach pioneered by Elinor Ostrom and her collaborators for studying commons arrangements in the natural environment (Ostrom 1990). The version of the framework set out in this chapter closely tracks the version published as chap. 1 of Governing Knowledge Commons (Frischmann, Madison, and Strandburg 2014), and in an earlier paper (Madison, Frischmann, and Strandburg 2010a), with some important updates and revisions added to reflect lessons learned in the course of conducting the case studies published in that book. By reproducing and further refining the framework here, we hope to inspire future researchers to adopt, extend, and continue to refine it.

The systematic approach to case study design and analysis provided by the knowledge commons framework aims to structure individual case studies in a useful and productive way and to make it possible eventually to produce generalizable results. Comparing and aggregating case studies performed according to the knowledge commons framework should enable an inventory of the structural similarities and differences between

Katherine J. Strandburg is the Alfred B. Engelberg Professor of Law and a Faculty Director of the Engelberg Center for Innovation Law and Policy at the New York University School of Law, New York, New York. Brett M. Frischmann is The Charles Widger Endowed University Professor in Law, Business and Economics at Villanova University Charles Widger School of Law, Villanova, Pennsylvania. Michael J. Madison is Professor of Law and Faculty Director of the Innovation Practice Institute at the University of Pittsburgh School of Law, Pittsburgh, Pennsylvania. Professor Strandburg acknowledges the generous support of the Filomen D'Agostino and Max E. Greenberg Research Fund.

1 In prior work, we explained in substantial detail the need for a research framework for systematically studying knowledge commons; Governing Knowledge Commons (Frischmann, Madison, and Strandburg 2014) was a successful proof of concept. Governing Medical Knowledge Commons builds upon that work. This chapter does not aim to justify the GKC framework or research program; instead, it only provides an abbreviated discussion of the framework itself. For motivations, justifications, and comprehensive discussion of how the GKC framework relates to Ostrom's work and especially the IAD framework, please refer to our prior work. 
commons in different industries, disciplines, and knowledge domains and shed light on the underlying contextual reasons for the differences. This structured inquiry provides a basis for developing theories to explain the emergence, form, and stability of the observed variety of knowledge commons and, eventually, for designing models to explicate and inform institutional design. In addition, an improved understanding of knowledge commons should facilitate a more complete perspective on intellectual property (IP) law and policy and its interactions with other legal and social mechanisms for governing creativity and innovation.

\subsubsection{What Do We Mean by Knowledge Commons?}

"Knowledge commons" is shorthand. It refers to an institutional approach (commons) to governing the management or production of a particular type of resource (knowledge).

Commons refers to a form of community management or governance. It applies to resources and involves a group or community of people, but it does not denote the resources, the community, a place, or a thing. Commons is the institutional arrangement of these elements: "The basic characteristic that distinguishes commons from noncommons is institutionalized sharing of resources among members of a community" (Madison, Frischmann, and Strandburg 2010b: 841). Critically, commons governance is used by a wide variety of communities to manage many types of resources. Commons governance confronts various obstacles to sustainable sharing and cooperation. Some of those obstacles derive from the nature of the resources and others derive from other factors, such as the nature of the community or external influences. Communities can and often do overcome obstacles through constructed as well as emergent commons. Importantly, while commons-governed institutions generally offer substantial openness regarding both informational content and community membership, they usually impose some limits relating, for example, to who contributes, what contributions are incorporated into the shared pool, who may use the pooled knowledge, or how it may be used. The limitations imposed by a knowledge commons often reflect and help resolve the obstacles to sharing encountered in its particular context.

Knowledge refers to a broad set of intellectual and cultural resources. In prior work, we used the term "cultural environment" to invoke the various cultural, intellectual, scientific, and social resources (and resource systems) that we inherit, use, experience, interact with, change, and pass on to future generations. To limit ambiguity and potential confusion, and to preserve the wide applicability of the framework, we currently use the term "knowledge." We emphasize that we cast a wide net and that we group together information, science, knowledge, creative works, data, and so on.

Knowledge commons is thus shorthand for the institutionalized community governance of the sharing and, in many cases, creation of information, science, knowledge, data, and other types of intellectual and cultural resources. Demand for governance institutions arises from a community's need to overcome various social 
dilemmas associated with producing, preserving, sharing, and using information, innovative technology, and creative works.

Some initial illustrations of knowledge commons illustrate the variety of institutional arrangements that may be usefully studied using the GKC framework. Consider the following examples from the Governing Knowledge Commons book:

- Nineteenth-century journalism commons

- Astronomical data commons

- Early airplane invention commons

- Entrepreneurial/user innovation commons

- Genomic data commons

- Intellectual property pools

- Legispedia (a legislative commons)

- Military invention commons

- News reporting wire services,

- Online creation communities

- Open source software

- Rare disease research consortia

- Roller derby naming commons

- Wikipedia

At first glance, these examples may appear to be disparate and unrelated. Yet we believe that a systematic, comprehensive, and theoretically informed research framework offers significant potential to produce generalizable insights into these commons phenomena. Comparative institutional investigation of knowledge commons is relevant to understanding social ordering and institutional governance generally, including via intellectual property law and policy.

\subsection{INTELLECTUAL PROPERTY, FREE RIDING, COMMONS, AND THE GKC FRAMEWORK FOR EMPIRICAL STUDY}

As discussed in more detail in our earlier work, our approach to the study of knowledge commons governance is founded on three basic propositions, which we simply state here, having elaborated upon them in detail in our earlier work: First, traditional intellectual property "free rider" theory fails to account for cooperative institutions for creating and sharing knowledge that are prevalent (and perhaps increasingly so) in society. Policy based solely on this traditional view is thus likely to fail to promote socially valuable creative work that is best governed by a commons approach and may, at least in some circumstances, impede such work. Second, the widespread recognition of certain well-known successes of the commons approach, such as open source software, can itself be problematic when it ignores the significant governance challenges that often arise for such institutions. A more nuanced appreciation of the benefits and challenges of knowledge commons 
governance is necessary for wise policy choices. Third, the development of a more sophisticated approach to knowledge commons governance will require systematic empirical study of knowledge commons governance "in the wild."

\subsubsection{The IAD Framework for Studying Natural Resource Commons}

To develop a systematic empirical approach for studying knowledge commons governance, we turned to the work of Elinor Ostrom and collaborators, who faced a similar scholarly challenge in understanding natural resource commons, such as lakes and forests. There, simplistic "tragedy of the commons" models suggested a policy space bifurcated between private property and government subsidy or topdown regulation. Real-world observation of well-functioning commons governance arrangements exposed the inadequacies of such a simplistic theoretical approach to the variety and complexity of social and natural contexts involved.

In response, Ostrom and her collaborators developed the Institutional Analysis and Development (IAD) framework for structuring and analyzing case studies of natural resource commons and situating them with respect to private property and government subsidy or regulation. A framework approach is pre-theoretical, in that it "helps to identify the elements (and the relationships among these elements) that one needs to consider for institutional analysis. Frameworks ... provide the most general set of variables that should be used to analyze all types of settings relevant for the framework ... They attempt to identify the universal elements that any relevant theory would need to include" (Ostrom 2005: 28-29). It thus avoids the myopia (and mistakes) that can result from forcing the complexity of real-world social behavior into a single theory or model (such as "tragedy of the commons" or "free riding") and opens up the theoretical space so that researchers can identify salient factors and social dilemmas that should drive theoretical understanding. A framework approach also systematizes the development of general observations that can be of use both for policymaking and for understanding how to craft and apply more specific theories and models for particular cases.

The IAD framework centers on the concept of an "action arena," in which relevant actors interact with one another to deal with the social dilemmas associated with sharing and sustaining a particular natural resource in light of its characteristics and the environment and community in which it is situated. Interactions within an action arena are governed by "rules-in-use," which may be formal or informal, to produce particular outcomes.

Structuring a case study according to the IAD framework involves asking specific questions about the resources, actors, environment, rules-in-use, and other aspects of a particular commons arrangement that assist the researcher in drilling down into the facts of a particular case (Ostrom 2005: 13-14). The IAD framework thus allows researchers to move beyond the overly general assumptions of the "tragedy of the commons" story to investigate how resources actually are governed, structuring the empirical inquiry so that comparisons are possible, while avoiding unwarranted 
by applying the IAD framework to structured case studies, natural resources researchers developed theories and models for particular commons situations, designed experiments to test those theories, and used statistical methods to look for regularities across cases. Based on this empirical work, Ostrom advanced a set of design principles for successful natural resource commons (Ostrom et al. 2007: 15181-82).

\subsubsection{Developing a Framework for the Study of Knowledge Commons Governance}

Several years ago, Ostrom and her colleagues began to apply the IAD framework to investigate the management of collections of existing knowledge resources (Ostrom and Hess 2007). A direct application of the IAD framework to knowledge commons had its limitations, however. In particular, it neglected (or, at least, did not emphasize) certain ways in which knowledge resources and their associated communities differ from natural resources and the communities that use and manage them. In creating the Governing Knowledge Commons (GKC) framework, we identified several important distinctions and modified and extended the IAD framework to better account for the distinctive character of knowledge commons.

First, knowledge resources must be created before they can be shared. Individual motivations for participating in knowledge creation are many and various, ranging from the intrinsic to the pecuniary. Motivations may also be social and thus interwoven with the character of the community. Therefore, knowledge commons often must manage both resource production and resource use within and potentially beyond the commons community.

Second, those who participate in knowledge production necessarily borrow from and share with others - and not in any fixed or small number of ways. Indeed, it may be impossible to divest oneself of knowledge to which one has been exposed. Inevitably, the intellectual products of past and contemporary knowledge producers serve as inputs into later knowledge production. As a result, knowledge commons must cope with challenges in coordinating and combining preexisting resources to create new knowledge.

Third, because knowledge is nonrivalrous once created, there is often social value in sharing it beyond the bounds of the community that created it. The public goods character of knowledge resources necessitates consideration not only of dynamics internal to a commons community but also of relationships between those communities and outsiders. Knowledge commons must confront questions of openness that may generate additional social dilemmas (Madison, Frischmann, and Strandburg 2009: 368-69).

Fourth, intangible knowledge resources are not naturally defined by boundaries that limit their use. Depending upon the knowledge at issue and the circumstances of its creation, creators may or may not be able to limit use by others as a practical matter, for example, through secrecy. In essence, the boundaries of knowledge resources are built rather than found. Boundaries come from at least two sources. Intangible knowledge resources often are embodied in tangible forms, which may create bound- 
other social practices may create boundaries around knowledge resources, as, for example, in the case of the "claims" of a patent. The creation of boundaries is partly within and partly outside the control of the members of a knowledge commons community and generates a series of social dilemmas to be resolved.

Fifth, the nonrivalry of knowledge and information resources often rides on top of various rivalrous inputs (such as time or money) and may provide a foundation for various rivalrous outputs (such as money or fame). Knowledge commons must confront the social dilemmas associated with obtaining and distributing these rivalrous resources.

Sixth, knowledge commons frequently must define and manage not only these resources but also the make-up of the community itself. Knowledge commons members often come together for the very purpose of creating particular kinds of knowledge resources. The relevant community thus is determined not by geographical proximity to an existing resource, but by some connection - perhaps of interest or of expertise to the knowledge resources to be created. Moreover, the characteristics of the knowledge created by a given community ordinarily are determined, at least to some extent, by the community itself. Thus, neatly separating the attributes of the managed resources from the attributes and rules-in-use of the community that produces and uses them is impossible.

Finally, because of the way in which knowledge resources and communities are cocreated, both tend to evolve over time. Thus, to understand knowledge commons governance, it is often crucial to engage with the particular narratives of the community, which may be grounded in storytelling, metaphor, history, and analogy. The property scholar Carol Rose emphasizes the role of narratives, especially of origin stories, in explaining features of property regimes that are not determinable strictly on theoretical or functional grounds, particularly if one assumes that everyone begins from a position of rational self-interest (Rose 1994: 35-42). The stories that are told about knowledge commons, and by those who participate in them, are instructive with respect to understanding the construction, consumption, and coordination of knowledge resources. Particular histories, stories, and self-understandings may be important in constructing the social dilemmas that arise and in determining why a particular knowledge commons approaches them in a particular way.

The GKC framework for conducting case-based research and collecting and comparing cases is intended to be inclusive, in that various disciplinary perspectives, including law, economics, sociology, and history, may be relevant to applying it to particular cases. By design, and in light of our still-nascent understanding of knowledge commons governance, the GKC framework remains a work in progress, which will be most valuable if it is developed and honed as more examples are studied. Indeed, the description here already reflects some reorganization and fine-tuning of our initial take on the framework as presented in earlier work (Madison, Frischmann, and Strandburg 2010a).

We illustrate the GKC framework and its relationship to the IAD framework with the flow charts in Figures 1.1 and 1.2. 


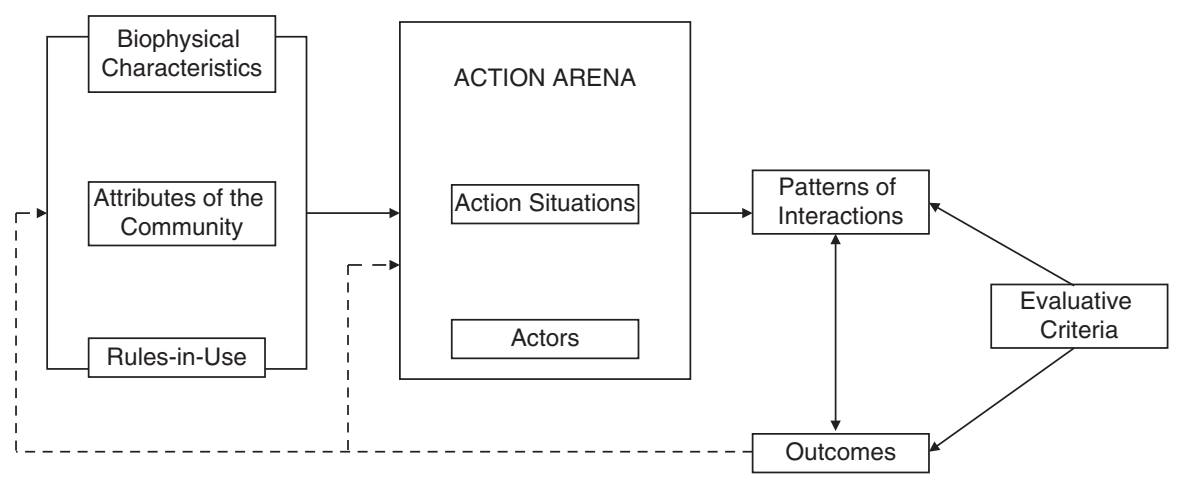

FIGURE 1.1 Based on a flow chart used to illustrate the IAD framework (Ostrom 2005: 15). It pictures the way in which relevant variables, including the biophysical characteristics of the natural resource, the attributes of the community, and the rules-in-use in the community influence the way in which actors interact in particular action situations to produce patterns of interactions and outcomes, which may be evaluated from a social perspective through evaluative criteria. The dotted lines illustrate the way in which the outcomes from a given

pattern of interactions can influence the input variables, for example, by leading to destruction or sustainability of the resource or to modifications of the rules-in-use because the community is dissatisfied with the outcomes.

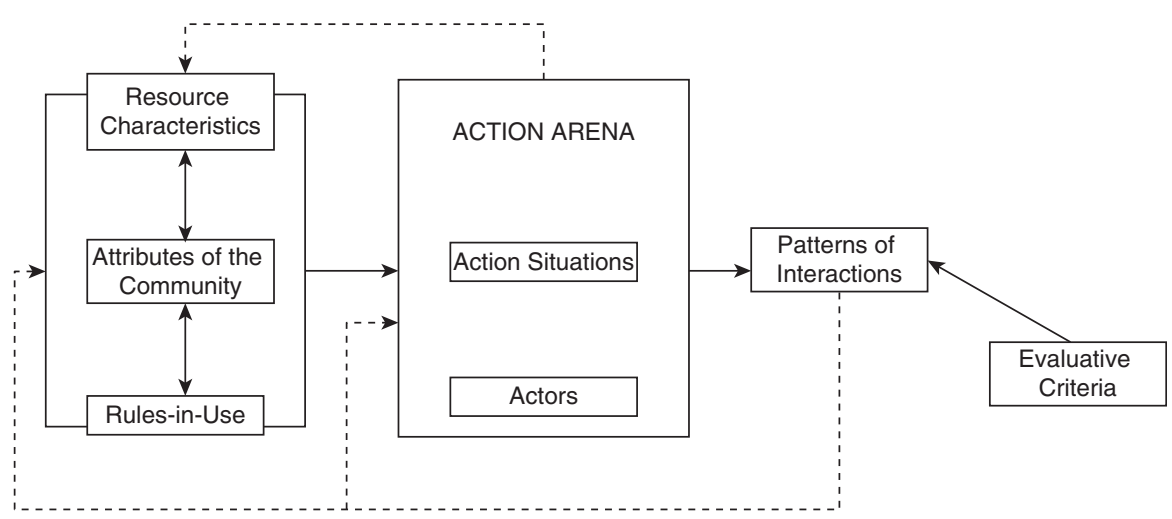

FIGURE 1.2 The GKC framework. Because of the more complex relationships among resources, participants, and governance structures in knowledge commons, relevant attributes may not divide as neatly into categories as they do when one is describing a pool of natural resources. Thus, in the leftmost part of the chart, we connect the resources characteristics, community attributes, and rule-in-use to emphasize their interrelated and contingent character. The dotted line leading directly from the action arena to resource characteristics illustrates the way in which interactions in the action arena, by creating intellectual resources, feed directly back into resource characteristics without being mediated by ongoing patterns of interactions. 
Figure 1.2 also collapses a distinction made in the original IAD framework between "patterns of interactions" that follow from the action arena and outcomes that follow from the patterns of interaction. The patterns of interactions generated by the formal and informal rules systems of a knowledge commons are often inseparable from the outcomes it produces. How people interact with rules, resources, and one another, in other words, is itself an outcome that is inextricably linked with and determinative of the form and content of the knowledge or informational output of the commons. In an open source software project, for example, the existence and operation of the open source development collaborative, the identity of the dynamic thing called the open source software program and the existence and operation of the relevant open source software license and other governance mechanisms are constitutive of one another.

With this general picture in mind, we now lay out the GKC framework for empirical study of knowledge commons in the box, "Knowledge Commons Framework and Representative Research Questions." More detail about the various aspects of the framework is provided in our earlier work and illustrated in the case studies in this book.

During the course of a case study, the framework of questions summarized in the box is used in two ways. First, it is used as a guide in planning interviews with relevant actors, documentary research, and so forth. Second, it is used as a framework for organizing and analyzing the information gained from interviews, relevant documents, and so forth. Though we list the various "buckets" of questions in the framework sequentially, in practice the inquiry is likely to be iterative. Learning more about goals and objectives is likely to result in the identification of additional shared resources; understanding the makeup of the community will lead to new questions about general governance, and so forth.

\section{Knowledge Commons Framework and Representative Research Questions}

\section{BACKGROUND ENVIRONMENT}

- What is the background context (legal, cultural, etc.) of this particular commons?

- What is the "default" status, in that background context, of the sorts of resources involved in the commons (patented, copyrighted, open, or other)?

\section{ATTRIBUTES}

\section{Resources}

- What resources are pooled and how are they created or obtained?

- What are the characteristics of the resources? Are they rival or nonrival, tangible or intangible? Is there shared infrastructure? 
- What technologies and skills are needed to create, obtain, maintain, and use the resources?

\section{Community Members}

- Who are the community members and what are their roles?

- What are the degree and nature of openness with respect to each type of community member and the general public?

\section{Goals and Objectives}

- What are the goals and objectives of the commons and its members, including obstacles or dilemmas to be overcome?

- What are the history and narrative of the commons?

\section{GOVERNANCE}

- What are the relevant action arenas and how do they relate to the goals and objective of the commons and the relationships among various types of participants and with the general public?

- What are the governance mechanisms (e.g., membership rules, resource contribution or extraction standards and requirements, conflict resolution mechanisms, sanctions for rule violation)?

- Who are the decision makers and how are they selected?

- What are the institutions and technological infrastructures that structure and govern decision making?

- What informal norms govern the commons?

- How do nonmembers interact with the commons? What institutions govern those interactions?

- What legal structures (e.g., intellectual property, subsidies, contract, licensing, tax, antitrust) apply?

\section{PATTERNS AND OUTCOMES}

- What benefits are delivered to members and to others (e.g., innovations and creative output, production, sharing, and dissemination to a broader audience, and social interactions that emerge from the commons)?

- What costs and risks are associated with the commons, including any negative externalities? 


\section{REFERENCES}

Boyle, James, The Public Domain: Enclosing the Commons of the Mind (Yale University Press 2008).

Eggertsson, Thráinn, Response: Mapping Social Technologies in the Cultural Commons, 95 Cornell L. Rev. 711 (2010).

Frischmann, Brett M., Cultural Environmentalism and The Wealth of Networks, 74 U. Chi. L. Rev. 1083 (2007).

Frischmann, Brett M., Madison, Michael J., and Strandburg, Katherine J. (eds.), Governing Knowledge Commons (Oxford University Press 2014).

Gordon, Wendy J., Response: Discipline and Nourish: On Constructing Commons, 95 Cornell L. Rev. 733 (2010).

Hess, Charlotte, Constructing a New Research Agenda for Cultural Commons, in Cultural Commons: A New Perspective on the Production and Evolution of Cultures 19 (Enrico Bertacchini et al. eds., Edward Elgar Publishing 2012).

Hyde, Lewis, Common as Air: Revolution, Art, and Ownership (Farrar, Straus and Giroux 2010).

Macey, Gregg P., Response: Cooperative Institutions in Cultural Commons, 95 Cornell L. Rev. 757 (2010).

Madison, Michael J., Frischmann, Brett M., and Strandburg, Katherine J., Constructing Commons in the Cultural Environment, 95 Cornell L. Rev. 657 (2010).

Merges, Robert P., Response: Individual Creators in the Cultural Commons, 95 Cornell L. Rev. 793 (2010).

Mokyr, Joel, The Gifts of Athena: Historical Origins of the Knowledge Economy (Princeton University Press 2002).

Ostrom, Elinor, Response: The Institutional Analysis and Development Framework and the Commons, 95 Cornell L. Rev. 807 (2010).

Ostrom, Elinor, and Charlotte Hess, A Framework for Analyzing the Knowledge Commons, in Understanding Knowledge as a Commons: From Theory to Practice (Charlotte Hess and Elinor Ostrom eds., MIT Press 2007).

Perzanowski, Aaron, and Kate Darling (eds.), Creativity without Law: Challenging the Assumptions of Intellectual Property (New York University Press 2017).

Solum, Lawrence B., Response: Questioning Cultural Commons, 95 Cornell L. Rev. 817 (2010). 